\title{
INSPEÇÃO REMOTA DE ESTRUTURAS COM RECURSO A VANT E INTEGRAÇÃO EM MODELOS BIM
}

\author{
Diogo Ribeiro ${ }^{(1)}$, Ricardo Santos ${ }^{(1)}$, Óscar Moreira ${ }^{(2)}$, Anderson Shibasaki ${ }^{(3)}$, Hélio \\ Teixeira $^{(4)}$, Michiel Bienens ${ }^{(5)}$, Nuno Topa ${ }^{(4)}$
}

(1) CONSTRUCT-LESE, ISEP/ISEPBIM, Porto

(2) ISEP/ISEPBIM, Porto

(3) Universidade Presbiteriana Mackenzie, São Paulo

(4) ISEP, Porto

(5) KU Leuven, Faculty of Engineering Technology, Leuven

\begin{abstract}
Resumo
O presente artigo descreve uma metodologia de inspeção remota de estruturas com recurso a Veículos Aéreos Não-Tripulados (VANT) e assente no processamento automatizado de imagens digitais, incluindo a sua posterior integração em modelos BIM. A metodologia proposta é baseada na aplicação de técnicas avançadas de processamento de imagem desenvolvidas em MATLAB que permitem de modo automático realizar a identificação de patologias em estruturas de betão. A metodologia de inspeção desenvolvida é aplicada ao fuste da torre de telecomunicações do Monte da Virgem localizada em VN Gaia. Os resultados obtidos demonstraram a eficiência e robustez da metodologia na identificação das diversas patologias, nomeadamente, ataques biológicos, eflorescências, fissuras e armaduras expostas, além do seu mapeamento em modelo BIM. A introdução dos resultados das inspeções em modelos BIM possibilitará no futuro melhorias significativas no acompanhamento do estado de conservação das estruturas e na sistematização dos processos de manutenção das mesmas.
\end{abstract}

\section{Introdução}

A inspeção visual é a técnica mais utilizada pelos gestores das infraestruturas para a avaliação do estado de conservação do património construído. Esta técnica clássica além de exigir a presença de técnicos especializados, requer, em situações de difícil acessibilidade, o recurso a equipamentos específicos do tipo plataformas móveis, gruas e andaimes, que aumentam o custo e o tempo de execução dos trabalhos de inspeção. Acresce que em muitos casos a própria segurança dos profissionais poderá ser colocada em risco.

É neste contexto que as técnicas de inspeção com recurso a Veículos Aéreos Não Tripulados (VANT), vulgarmente designados por drones, se tornam competitivas, não só pela flexibilidade em aceder a locais de difícil acesso, mas sobretudo pela redução dos custos e tempo de execução, uma vez que a inspeção é realizada através de levantamento fotográfico com apoio de camaras vídeo/fotográficas acopladas ao drone, e com menos pessoal técnico. 
As técnicas de inspeção mais avançadas com recurso a drones permitem realizar: i) a reconstituição 3D da geometria, recorrendo a ortomosaicos georreferenciados obtidos através de técnicas de fotogrametria [1], ii) a identificação automática de patologias, com base em ferramentas computacionais avançadas [2], e iii) a elaboração de relatórios de inspeção enviados ao gestor da infraestrutura [3].

Henriques et al. [4] realizaram o levantamento fotogramétrico tridimensional do paramento de uma barragem em betão, com base em imagens georreferenciadas captadas com um drone, para a identificação de zonas com presença de eflorescências. Com base na aplicação de técnicas de processamento de imagens foi possível realizar o histórico das áreas afetadas e otimizar as intervenções de manutenção. No âmbito de uma inspeção realizada com drones a uma ponte rodoviária constituída por tabuleiro em betão e pilares em madeira, Duque [5] concluiu que as imagens obtidas através de câmaras de elevada resolução, e processadas com ferramentas avançadas de processamento de imagem, foram eficientes na identificação de danos na ponte, sobretudo na deteção de fissuras, destacamentos e humidades do betão, e a corrosão das armaduras. $\mathrm{O}$ mesmo autor realizou com sucesso a validação dos resultados obtidos com os resultados de uma inspeção visual. Recentemente Kim et al. [6], Kim et al. [7] aplicaram técnicas de processamento de imagens baseadas em inteligência artificial, em particular redes neuronais convolucionais $(\mathrm{CNN})$, na identificação de fissuras no tabuleiro de uma ponte e na parede um edifício, respetivamente, às imagens recolhidas através de câmaras incorporadas em drones. Omar e Nehdi [8] realizaram inspeções a pontes rodoviárias com tabuleiros em betão armado com recurso a um drone equipado com câmaras térmicas. Este tipo de câmaras permitiram aumentar a eficiência na deteção de zonas em pré-delaminação, ainda não visíveis, e com armaduras em início de processo de corrosão. Os resultados obtidos foram muito promissores atendendo à elevada similaridade com os resultados de um ensaio de potencial elétrico realizado ao betão. Parente et al. [9] e Rakha e Gorodestsky [1] incorporaram no drone câmaras fotográficas de diferentes tipos, nomeadamente câmaras RGB, infravermelhos, térmicas e híper-espetrais, de modo a aumentar a eficiência na identificação de vários tipos de patologias. Pix4D [10] realizaram inspeções periódicas com recurso a drone ao paramento exterior em betão da torre de telecomunicações de Arqiva, no Reino Unido, tendo em vista o acompanhamento do desenvolvimento de uma fissura de grandes dimensões, identificada à cota $185 \mathrm{~m}$. O recurso a imagens georreferenciadas foi decisivo para a localização das coordenadas exatas da fissura e o seu acompanhamento ao longo do tempo. $\mathrm{O}$ autor destacou ainda as limitações na recolha de imagens devido aos ventos fortes e a interferências eletromagnéticas, facto que é habitual neste tipo de estruturas de elevada altura.

No presente trabalho pretende-se dar um contributo para o desenvolvimento de uma metodologia de identificação de patologias em estruturas existentes de betão com base na análise e processamento de imagens recolhidas com auxílio de um drone, e a sua posterior integração em modelos BIM. A metodologia é baseada em imagens georreferenciadas, de modo a assegurar a exata localização das patologias, e o mais possível automatizada, uma vez que recorre a voos pré-programados e ao processamento automático das imagens. A incorporação dos resultados de inspeções baseadas em drones em modelos BIM tem um caráter inovador e não está ainda reportado na bibliografia. 


\section{Metodologia de inspeção remota de estruturas com recurso a VANTs}

Na Fig. 1 apresenta-se esquematicamente uma proposta de metodologia para a inspeção de estruturas com recurso a veículos aéreos não tripulados (VANTs), assente no processamento e análise automatizada de imagens, e a sua posterior integração em modelos BIM.

1.

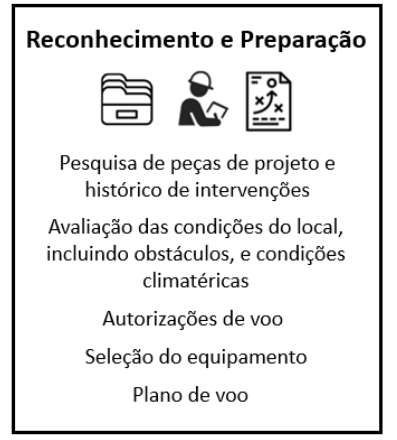

2.

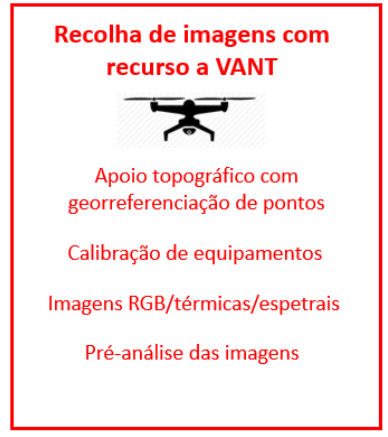

3.

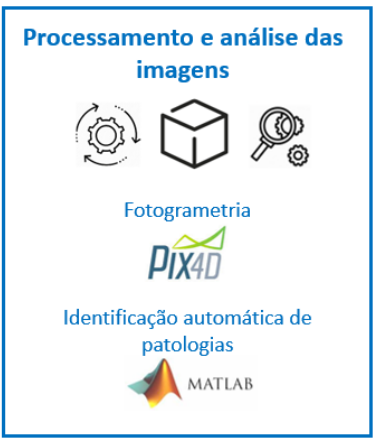

4.

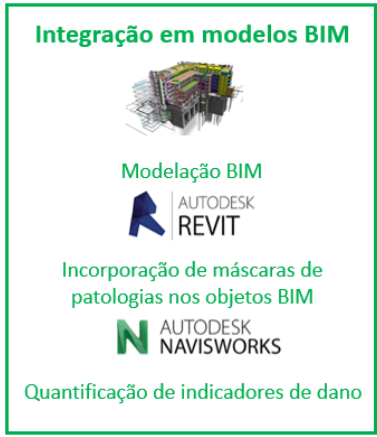

Figura 1: Metodologia de inspeção remota de estruturas com recurso a VANTs.

A fase 1, de reconhecimento e preparação, envolve, entre outros: i) a recolha de elementos documentais e a pesquisa do histórico de inspeções da estrutura alvo, ii) a visita ao local para avaliação das condições de acesso e de eventuais fatores de risco (obstáculos ao voo, condições de exposição ao vento, interferências eletromagnéticas), iii) a obtenção de autorizações de voo junto das entidades competentes (ANAC - Autoridade Nacional da Aviação Civil e AAN - Autoridade Aeronáutica Nacional), iv) seleção do corpo técnico e do equipamento de voo (drone, câmara, etc.), v) elaboração de um plano de voo incluindo a definição de zonas de aterragem/descolagem, o tempo de voo, o esquema de varrimento fotográfico da estrutura, a proximidade do drone ao alvo, entre outros.

A fase 2, de recolha de imagens com o drone, envolve, numa primeira etapa, o levantamento topográfico de precisão de alguns pontos fotogramétricos da estrutura. Esta etapa é essencial para a georreferenciação das imagens a recolher com o drone e a sua posterior incorporação no modelo BIM. Os pontos fotogramétricos devem ser dispostos de forma a abranger a totalidade da estrutura e podem ser materializados com o auxílio de alvos, ou, alternativamente, usados pontos notáveis e facilmente identificáveis da estrutura. A obtenção das coordenadas dos pontos fotogramétricos envolve a definição de pontos de apoio, em poligonal e com visibilidade para a estrutura, com o suporte de recetores GNSS (Global Navigation Satellite System) em módulo RTK (Real Time Kinematics), além do recurso a um teodolito eletrónico com capacidade de medição à distância para a obtenção das coordenadas dos alvos ou pontos notáveis.

Ainda na fase 2, numa segunda etapa, decorre a captura das imagens com recurso a um drone equipado com câmara vídeo/fotográfica. $\mathrm{O}$ drone deve atender a um conjunto de especificações, nomeadamente: grande alcance de controlo e operabilidade, resistência à ação do vento, capacidade de estabilização, incluir um sensor de proximidade de obstáculos, precisão de posicionamento por intermédio de sistema RTK, possibilidade de voo automático, capacidade de adaptar diferentes câmaras ou equipamentos, elevada autonomia, e câmaras de elevada resolução e capacidade de armazenamento. A recolha de imagens deve ser feita em segurança, 
mas o mais próximo quanto possível da estrutura, uma vez que distâncias mais curtas melhoram a resolução das imagens.

A fase 3, de processamento e análise das imagens, envolve duas etapas: i) a reconstituição de modelo geométrico 3D da estrutura com base nas imagens georreferenciadas e por aplicação de técnicas de fotogrametria disponibilizadas no programa Pix4D, e ii) a identificação automática de patologias com base nas imagens recolhidas e por aplicação de ferramentas de processamento de imagem disponibilizadas no Image Processing Toolbox do programa Matlab. Relativamente ao modelo geométrico 3D da estrutura, o programa Pix4D recorre a um algoritmo que acede às propriedades EXIF (EXchangeable Image File) de cada imagem (especificações da câmara, georreferenciação, resolução, etc.) para a criação de um modelo virtual de nuvem de pontos, utilizando os pontos comuns entre imagens. O modelo de nuvem de pontos captura, em muitas situações, objetos vizinhos ou de fundo da estrutura (árvores, céu, edifícios, etc.) que constam nas imagens e que deverão ser removidos. No que toca às ferramentas de processamento de imagens, estas foram direcionadas para a identificação de patologias típicas em estruturas de betão armado, nomeadamente de colonizações biológicas, fissuras, armaduras expostas e eflorescências. As ferramentas computacionais, desenvolvidas em ambiente Matlab para cada umas das patologias, são descritas nos trabalhos desenvolvidos por Shibasaki [11] e Teixeira [12]. As imagens provenientes da ferramenta Matlab de identificação de patologias, nas quais as patologias vêm assinaladas, são depois sobrepostas com as imagens originais, por intermédio de uma operação de overlay disponível no programa Pix4D. Os detalhes desta operação são detalhados em Shibasaki [11].

A fase 4, de integração da imagem com as patologias assinaladas em modelo BIM, envolveu também duas etapas: i) a incorporação da máscara associada a uma determinada patologia no modelo BIM desenvolvido na plataforma Autodesk Revit, e ii) a quantificação de indicadores de dano baseados em medições diretamente realizadas nas imagens. A sobreposição da imagem com as patologias assinaladas ao modelo BIM é realizada com recurso ao programa Autodesk Navisworks. Os indicadores de dano são calculados no programa Matlab e dizem respeito ao comprimento total de fissuras, à área total de colonizações biológicas ou eflorescências, entre outros. A evolução dos valores dos indicadores de dano permitirá acompanhar a evolução das diversas patologias identificadas, e, deste modo, auxiliar o gestor da infraestrutura na decisão acerca das medidas mais adequadas na manutenção da infraestrutura.

\section{Inspeção da torre de telecomunicações do Monte da Virgem}

\subsection{Descrição da estrutura}

A torre de telecomunicações do Monte da Virgem é uma torre de transmissão construída pela Altice/Portugal Telecom no ano de 1995 e localizada em Vila Nova de Gaia. A estrutura da torre é composta por um fuste de betão armado com $126 \mathrm{~m}$ de altura, e uma torre metálica de $51 \mathrm{~m}$ de altura, perfazendo uma altura total de $177 \mathrm{~m}$, constituindo a mais alta estrutura do género existente em Portugal (Fig. 2).

O fuste de betão armado apresenta a forma de um hiperboloide, com uma secção circular oca, e um diâmetro variável entre $14.3 \mathrm{~m}$, junto à base, e $7.7 \mathrm{~m}$ no topo. $\mathrm{O}$ fuste é dotado de cinco pisos técnicos, formados por uma laje em consola em betão pré-esforçado.

A torre metálica é constituída por uma treliça espacial de barras metálicas e formada por três troços ao longo da sua altura. O primeiro troço, para montagem do sistema de transmissão FM, 
tem 23 m de altura. O segundo troço, para montagem do sistema de transmissão VHF, apresenta $17 \mathrm{~m}$ de altura. O terceiro e último troço, para montagem do sistema de transmissão UHF, tem $12 \mathrm{~m}$ de altura, e está envolvido por uma manga cilíndrica em polyester.

A torre tem uma base em forma octogonal e é fixada ao fuste de betão por intermédio de chumbadouros. A transição da torre metálica para o fuste é realizada por meio de uma laje de betão.

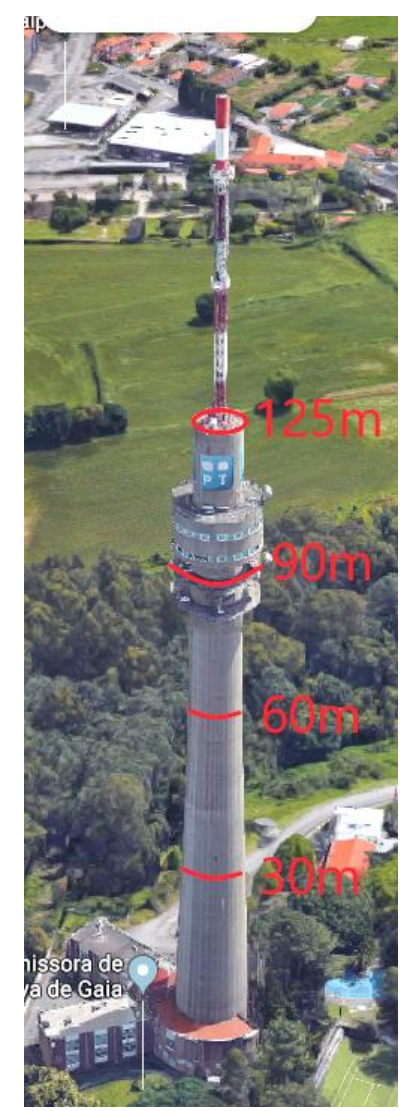

Figura 2: Torre de telecomunicações do Monte da Virgem.

\subsection{Reconhecimento e preparação}

A inspeção da torre incidiu no paramento exterior do fuste em betão armado, entre as cotas $30 \mathrm{~m}$ e $60 \mathrm{~m}$ em relação à base da estrutura (Fig. 2).

A torre do Monte da Virgem está localizada na Área 3 da Zona de Controlo de Tráfego Aéreo (CTR) do Porto. As regras de utilização de drones nesta zona permite voos sem a necessidade de uma autorização formal para alturas de operação inferiores a $80 \mathrm{~m}$ em relação à superfície, ou até à altura máxima do obstáculo natural/artificial existente considerando um raio de $75 \mathrm{~m}$ centrado na aeronave [13].

A técnica de voo utilizada foi o voo manual em virtude dos seguintes condicionalismos: i) possíveis interferências de sinal oriundas dos equipamentos transmissores em funcionamento na torre, ii) existência de árvores junto à base da torre, iii) geometria complexa do paramento da torre, em hiperboloide, o que dificulta a programação de voos automáticos, e iv) em virtude da proximidade da orla costeira, o vento e o eventual ataque de aves poderão constituir uma ameaça à segurança dos voos. 
A estratégia de recolha das imagens consistiu no varrimento fotográfico da superfície de betão em movimento de subida (de baixo para cima), um ajuste em movimento lateral, seguido de um movimento de descida (de cima para baixo). Estes movimentos repetem-se sucessivamente até se completar o levantamento fotográfico de todo o perímetro do fuste entre as cotas préestabelecidas.

No plano de voo, e conforme representação da Fig. 3, foram definidas zonas de observação para recolha de imagens, assinaladas a azul, bem como zonas de aterragem/descolagem, assinaladas a vermelho.

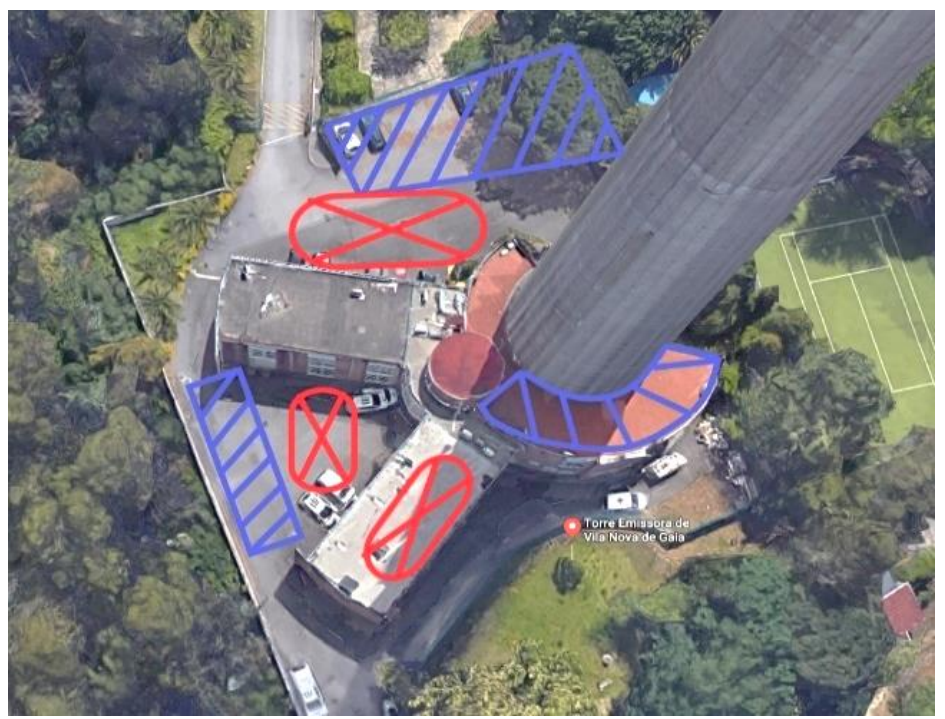

Figura 3: Plano de voo: zonas de observação e zonas de aterragem/descolagem.

\subsection{Recolha de imagens com VANT}

A recolha de imagens foi realizada com auxílio de um drone profissional da marca DJI, modelo Matrice 600 Pro (Fig. 4a). Trata-se de um hexacóptero com um peso entre $9.5 \mathrm{~kg}$ e $10 \mathrm{~kg}$, com um peso máximo em voo de $15.5 \mathrm{~kg}$, e com capacidade para atingir uma velocidade máxima de $65 \mathrm{~km} / \mathrm{h}$, altura máxima de $2500 \mathrm{~m}$, e uma autonomia de voo estimada de cerca de $30 \mathrm{~min}$ (por conjunto de baterias). A câmara fotográfica utilizada é da marca DJI, modelo ZenmuseX5, com uma resolução 4k, distância focal de $15 \mathrm{~mm}$ e um sensor com dimensões $15.5 \times 9.8$ mm. O gimbal utilizado garante a estabilização de imagem segundo os três eixos. A visualização das imagens e controlo remoto do drone foram realizados por intermédio de um monitor tátil de elevada resolução, do tipo Crystal Sky, com capacidade de armazenamento interno das imagens.

O levantamento topográfico dos pontos fotogramétricos localizados no fuste da torre foi executado com recurso a estação total, da marca Leica, modelo TRCP 1200 (Fig. 4b). Os pontos de apoio, num total de quatro, foram dispostos em poligonal e com visibilidade direta para o fuste da torre, e as suas coordenadas foram avaliadas com recurso a um recetor GNSS da marca STONEX S10, usado em modo RTK, com as correções fornecidas pela Rede Nacional de Estações Permanentes (ReNEP).

As imagens foram recolhidas com a câmara posicionada de forma obliqua em relação à estrutura, e a sua aquisição foi controlada por intermédio de um trigger manual, e realizada a cada $1.0 \mathrm{~m}$ de altura considerando uma sobreposição de 50\%. A distância do drone em relação 
ao fuste da torre foi variável e situada entre $5 \mathrm{~m}$ e $10 \mathrm{~m}$. No total foram recolhidas cerca de 6350 fotografias.

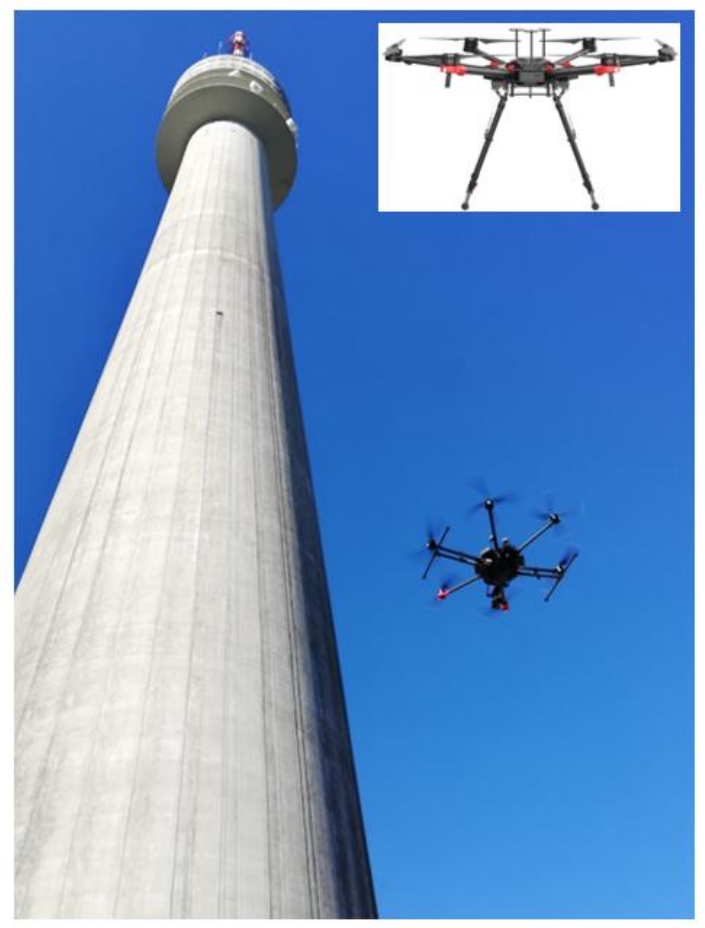

a)

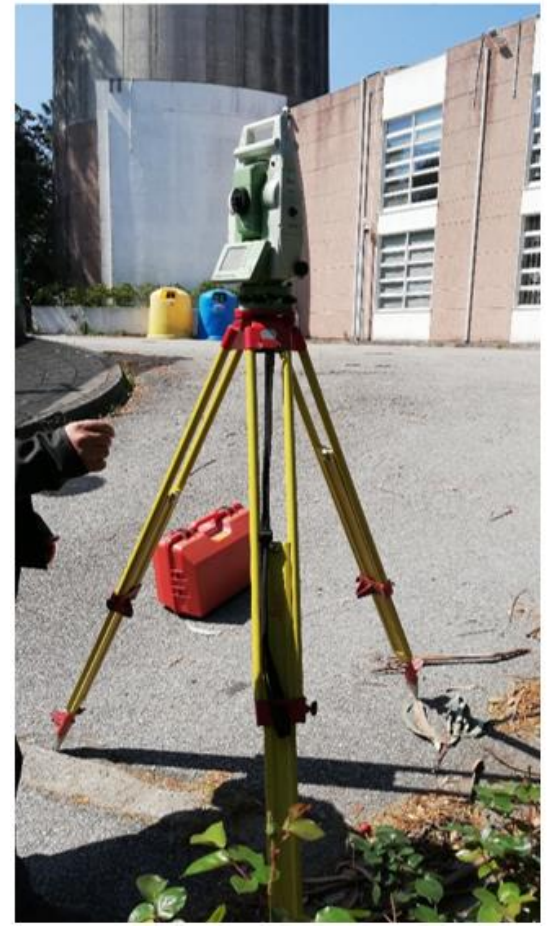

b)

Figura 4: Recolha de imagens com VANT: a) drone DJI Matrice 600 Pro em operação, b) levantamento topográfico.

\subsection{Processamento e análise das imagens}

O processamento das imagens captadas foi realizado com recurso ao programa Pix4D tendo em vista a reconstituição de modelo geométrico 3D da estrutura (Fig. 5a). A identificação automática de patologias com base nas imagens captadas e por aplicação de ferramentas da Image Processing Toolbox do programa Matlab encontra-se ilustrada na Fig. 6 para o caso de colonizações biológicas (Fig. 6a), de armaduras expostas (Fig. 6b) e eflorescências (Fig. 6c). As colonizações biológicas associadas à presença de líquenes e musgos foram sobretudo identificadas na zona do fuste voltada a Este, onde a exposição solar é menor. As armaduras expostas foram detetadas em casos pontuais e geralmente associadas a fenómenos de corrosão. As eflorescências foram identificadas em zonas de juntas de betonagem e em zonas onde o betão se apresenta mais poroso e permeável. Na Fig. 5b, a título exemplificativo, ilustra-se a sobreposição (overlay) das imagens do modelo 3D da torre com as imagens provenientes da ferramenta Matlab de identificação de colonizações biológicas, neste caso usando uma cor falsa (vermelho). Os detalhes desta operação vêm detalhados em Shibasaki [11]. 


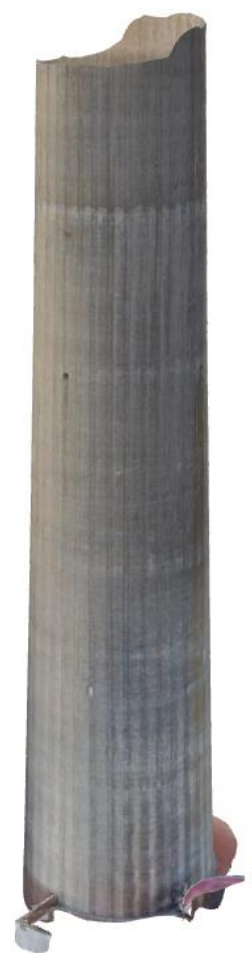

a)

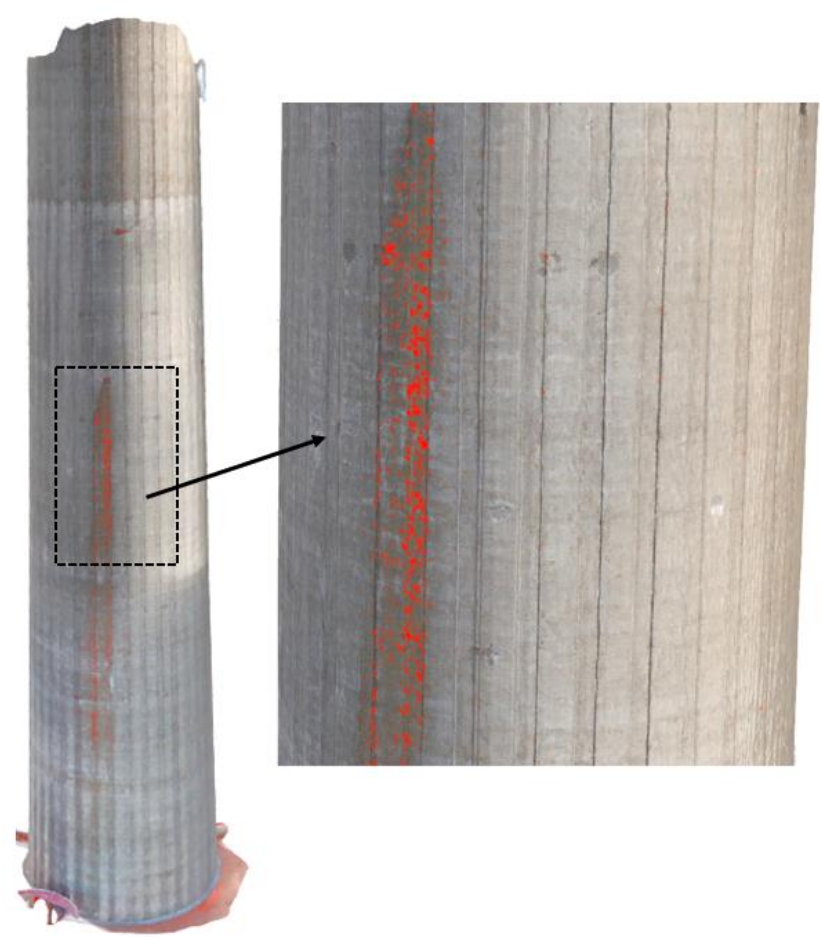

b)

Figura 5: Modelo geométrico 3D da estrutura reconstituído no programa Pix4D: a) perspetiva global, b) sobreposição com as colonizações biológicas (cores falsas).

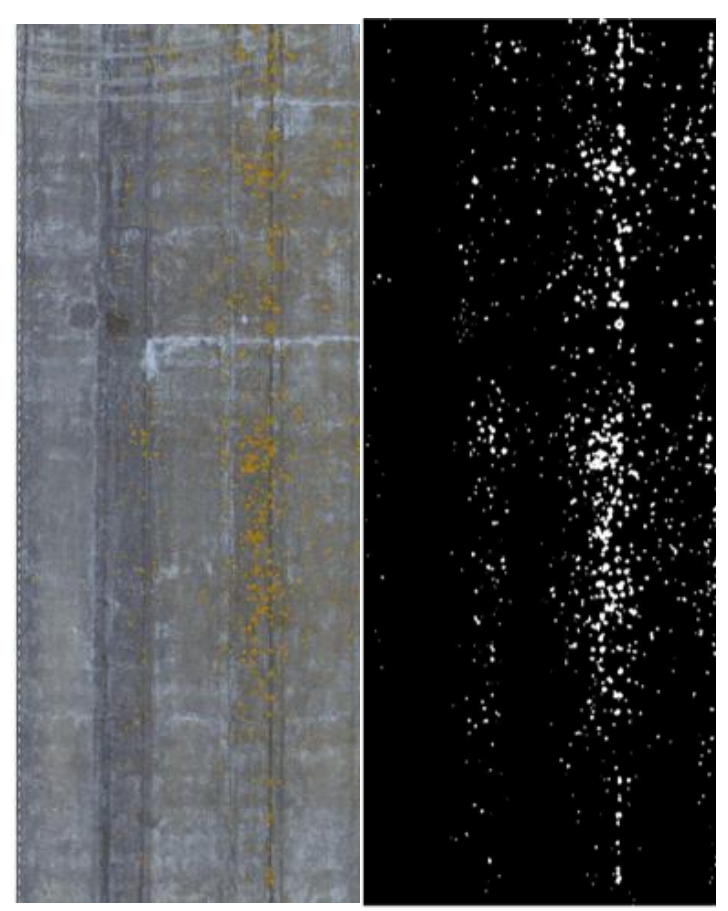

a)
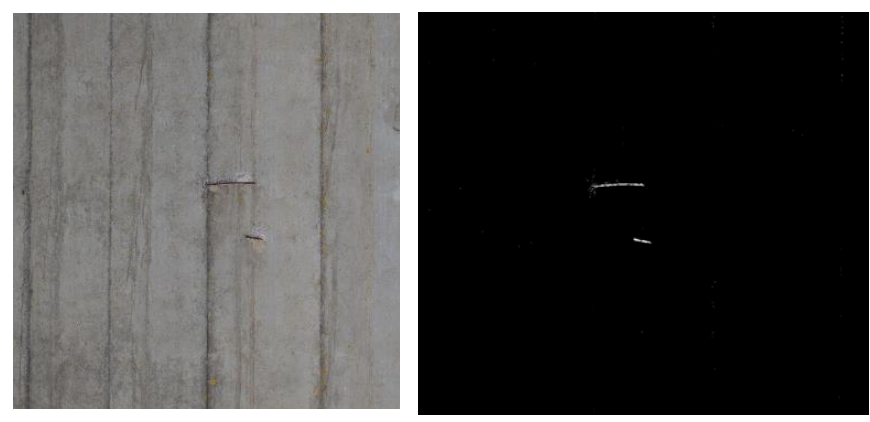

b)
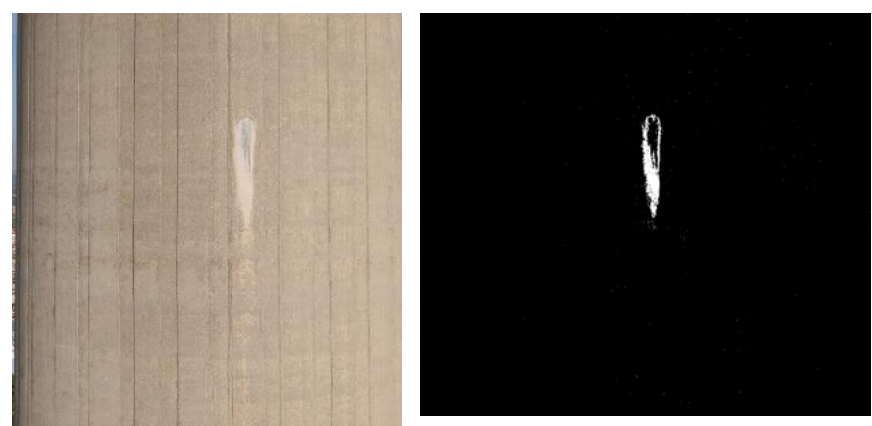

c)

Figura 6: Identificação automática de patologias com recurso ao Matlab Image Processing Toolbox (cores falsas): a) colonizações biológicas, b) armaduras expostas, c) eflorescências. 


\subsection{Integração em modelos BIM}

$\mathrm{O}$ modelo geométrico 3D da torre, incluindo as propriedades materiais e o faseamento do processo construtivo, foi desenvolvido em LOD 500 na plataforma Autodesk Revit (Fig. 7). A geração geométrica do fuste em betão foi realizada com auxílio da ferramenta de programação gráfica Dynamo, atendendo às limitações do Revit em gerar autonomamente o paramento em forma de hiperboloide. A geometria e as propriedades estruturais da torre metálica foram importadas de um modelo numérico existente e desenvolvido no programa Autodesk Robot. A incorporação das máscaras das várias patologias identificadas no modelo BIM é realizada com recurso ao programa Autodesk Navisworks. Na Fig. 7, a título exemplificativo, ilustra-se a máscara referente às colonizações biológicas sobre o paramento do fuste da torre entre as cotas $30 \mathrm{~m}$ e $60 \mathrm{~m}$.
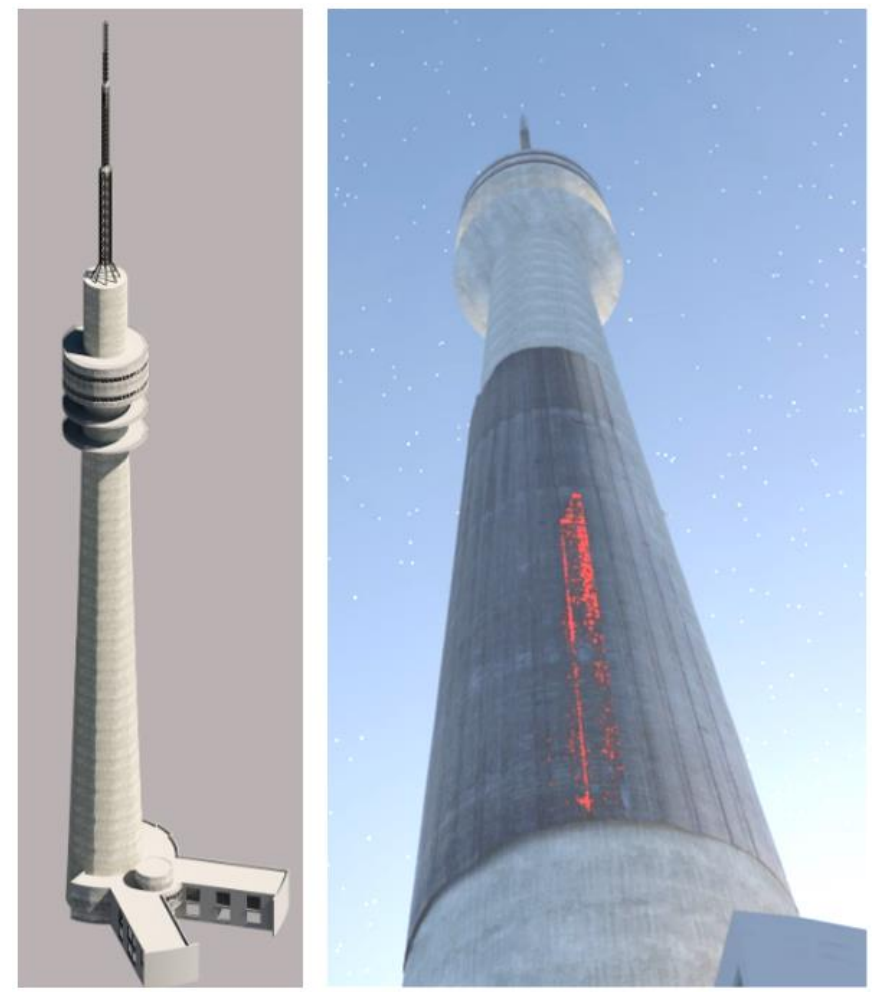

Figura 7: Modelo BIM da torre incluindo a máscara das colonizações biológicas.

\section{Conclusões e desenvolvimentos futuros}

O presente artigo descreveu uma metodologia de integração em modelos BIM da informação proveniente de inspeções a estruturas de betão. A metodologia é baseada na recolha de imagens georreferenciadas com recurso a VANTs e o seu processamento com base em ferramentas computacionais avançadas que possibilitam a identificação automática de patologias, e a sua integração em modelos BIM.

A metodologia proposta é baseada em quatro etapas, o reconhecimento e preparação, a recolha de imagens com auxílio de VANT, o processamento e análise de imagens e a integração em modelos BIM. 
A aplicação da metodologia à inspeção remota do fuste de betão da torre de telecomunicações do Monte da Virgem demonstrou robustez e eficiência sobretudo na disponibilização, em tempo útil, dos resultados da inspeção ao gestor da infraestrutura, tendo como meio de comunicação o modelo BIM. O uso regular, em períodos de tempo intervalados, da metodologia de inspeção proposta, permitirá ao gestor da infraestrutura acompanhar a evolução das patologias identificadas a partir do histórico de indicadores de dano, possibilitando a realização de eventuais intervenções de manutenção com menores custos e de modo mais ágil.

$\mathrm{Na}$ perspetiva de trabalhos futuros, considera-se a possibilidade de embarcar nos drones câmaras multiespectrais capazes de registar espectros de luz além do visível e dessa forma melhorar a capacidade de identificar eventuais patologias. É também previsível o desenvolvimento e aplicação de estratégias de inteligência artificial, baseadas em redes neuronais convolucionais, na identificação de fissuras e armaduras expostas.

\section{Agradecimentos}

Os autores agradecem à Altice, em particular ao Eng. Jorge Garcia, pelo apoio à realização das campanhas de inspeção na torre do Monte da Virgem, à HP Drones, em particular ao Hanniel Pontes, pelo empréstimo de equipamento para a realização das campanhas, e ao Rafael Cabral e Gabriel Saramago, pelo apoio na operação do drone e preparação das campanhas de inspeção.

\section{Referências}

[1] T. Rakha, A. Gorodestsky, "Review of Unmanned Aerial System (UAS) applications in the built environment: Towards automated building inspection procedures using drones", Automation in Construction, vol. 93, pp. 252-264, September 2018. https://doi.org/10.1016/j.autcon.2018.05.002.

[2] S. Sankarasrinivasan, E. Balasubramanian, K. Karthik, U. Chandrasekar, R. Gupta, "Health monitoring of civil structures with integrated UAV and image processing system", Procedia Computer Science, vol. 54, pp. 508-515, 2015. doi: 10.1016/j.procs.2015.06.058.

[3] M. Kovacevic, K. Gavin, I. Oslakovic, M. Bacic, "A new methodology for assessment of railway infrastructure condition", Transportation Research Procedia, vol. 14, pp. 19301939, 2016. doi: 10.1016/j.trpro.2016.05.160.

[4] M. Henriques, D. Roque, "Unmanned Aerial Vehicles (UAV) as a Support to Visual Inspections of Concrete Dams" in DAM WORLD Conference (II), 2015.

[5] L. Duque, "UAV-Based Bridge Inspection and Computational Simulations", dissertação do Mestrado em Engenharia Civil, South Dakota University, EUA, 2017.

[6] H. Kim, J. Lee, E. Ahn, S. Cho, M. Shin, S-H. Sim, "Concrete Crack Identification Using a UAV Incorporating Hybrid Image Processing”, Sensors, vol. 17, pp. 2052, 2017. doi:10.3390/s17092052.

[7] I-H. Kim, H. Jeon, S-C. Baek, W-H. Hong, H-J. Jung, "Application of Crack Identification Techniques for an Aging Concrete Bridge Inspection Using an Unmanned Aerial Vehicle", Sensors, vol. 18, pp. 1881, 2018. doi:10.3390/s18061881. 
[8] T. Omar, M. Nehdi, "Remote sensing of concrete bridge decks using unmanned aerial vehicle infrared thermography", Automation in Construction, vol. 83, pp. 360-371, November 2017. https://doi.org/10.1016/j.autcon.2017.06.024.

[9] D. Parente, N. Felix, A. Picanço, "Utilização de veículo aéreo não tripulado (VANT) na identificação de patologia superficial em pavimento asfáltico", Revista ALCONPAT, vol. 7 (2), pp. 160-171, Maio 2017. http://dx.doi.org/10.21041/ra.v7i1.161.

[10]Pix4D, "Mapping, modeling and inspecting the UK's tallest tower", 2016, disponível online: https://www.pix4d.com/blog/drone-inspections-tallest-tower-uk.

[11]A. Shibasaki, "Inspeção da torre do monte da virgem com o auxílio de veículo aéreo não tripulado", dissertação do Mestrado em Engenharia Civil -Estruturas, ISEP, Porto, 2019.

[12]H. Teixeira, "Inspeção da torre do monte da virgem com o auxílio de veículo aéreo não tripulado", dissertação do Mestrado em Engenharia Civil - Construções, ISEP, Porto, 2019.

[13]Decreto de Lei $n^{\circ}$ 238/2916 de 14 de Dezembro emitido pela Autoridade Nacional da Aviação Civil. Diário da República: série II, No 1093, pp. 36613-36622 (2016). Acedido a 08 ago. 2020. Disponível em www.dre.pt. 